\title{
Exploring the Factors Affecting MOOCs Continuance Intention: The Role of Design Quality
}

\author{
Genfu Yang* \\ School of digital media and design \\ HangZhou Dianzi University \\ HangZhou, China \\ ygfsn@hdu.edu.cn
}

\author{
Qian Sun \\ School of digital media and design \\ HangZhou Dianzi University \\ HangZhou, China \\ 70665060@qq.com
}

\begin{abstract}
Massive Open Online Courses (MOOCs) is a rapidly growing paradigm of educational provision. The success of MOOCs depends on learners' continued usage. Drawing upon the expectation confirmation model on information technology (ECM-IT) and combining MOOCs platform design quality, a theoretical model for studying learners' continuance intentions toward participation in MOOCs was developed. Based on survey data from 271 respondents, structural equation modeling was employed to assess the model. The results of this analysis indicate that perceived usefulness, satisfaction, course organization, learning analysis and social interaction were significant antecedents of the continuance intention of individuals, but, learning evaluation was not significant influence on the continuance intention of learners. The results contribute to the extant literatures in the context of MOOCs learning by identifying the critical MOOCs design quality factors, and provide several guidelines to the administrators of MOOCs services regarding to platform design, courses quality, socialized interaction and so on. Theoretical and practical implications are discussed.
\end{abstract}

Keywords-MOOCs design quality; continuance intention; learning analysis; learning evaluation

\section{INTRODUCTION}

Massive Open Online Courses (MOOCs) is a rapidly growing paradigm of educational provision, the number of MOOCs has increased in recent years. MOOCs holding the potential to open up access to world class teaching and educational resources beyond geographical and social boundaries. However, despite public enthusiasm for MOOCs, it has been observed that MOOCs suffer from enormous dropout rates (Adams \& Williams, 2013; Jia Jiyou et al., 2014; Xing, et al., 2016). Research shows that more than $90 \%$ of students attending MOOCs dropout before complete their (Breslow et al., 2013; Hewand Cheung, 2014; Ho et al., 2014). Considering the issue of MOOCs dropout and non-completion rates, a subject of great concern has been centered on issues of learning and teaching. Khaled M. Alraimi et al. (2015) analyzed the impact of the openness and the reputation of top universities on learners' continuance intention.Yang Genfu (2016) integrated the information systems continuance expectation-confirmation model (Bhattacherjee,2008) and the theory of selfdetermination (2008), analyzed the intention to using MOOCs. Liqiang Huang (2017) explored how MOOCs' technological factors in in three dimensions (i.e., course vividness, teacher

HangZhou Dianzi University Humanities and Social Science Fund(2017B08).Zhejiang Information and Economic and Social Development Research Center(16XXHJD08). subject knowledge, and interactivity) influence students' revisiting of MOOCs, and also takes course difficulty into consideration and investigates the interactive effects of course difficulty on the main factors identified above.

Some studies believe that it is necessary to promote the design quality of MOOCs and to put forward the criterion of design quality on MOOCs. For example, Ferncxndez et al.(2015)proposed the MOOCs education quality comprehensive evaluation system. Jiang et al. (2016) designed MOOCs teaching design and evaluation system, including user interface, video content, interactive tools, learning analysis and others quality factors from the two dimensions of teaching and technology. Tang et al. (2017) from the course organization, electronic assessment, peer assessment, user interface, video content, learning analysis and social interaction of MOOCs to evaluate the design quality of MOOCs, in order to improve the quality of MOOCs design.

In addition, MOOCs are classes delivered in an online environment with important differences from traditional education mode. As a new education model, MOOCs rely on technology to transfer information from teachers to students (Lee \& Lehto,2013).In other words, students learning mainly from MOOCs platform through technology(i.e., internet access, watch the video, discuss on forum, interaction with peer or teacher through web or social media). Therefore, the design quality of MOOCs platform plays an extremely important role in attracting and maintaining learners. In summary, this paper based on ECM-IT model, combined with MOOCs design quality factor in five dimensions (i.e., curriculum organization, video quality, learning evaluation, learning analysis, social interaction). This paper will primary discusses two questions:

1) The design quality factors how to influence on learners' continuance intention to using MOOCs?

2) Perceived usefulness and satisfaction how to affect learners' continuance intention to using MOOCs?

\section{RESEARCH MODEL AND HyPOTHESES}

Using the theoretical background of the ECM-IT, design quality of MOOCs, we propose a research model that identifies several attributes as predictors of MOOCs continuance intention. The relationships between these constructs are integrated in the conceptual model depicted in figure 1.The basic assumption is that MOOCs continuance intention is jointly determined by perceived usefulness and satisfaction, which are functions of design quality of MOOCs. Curriculum 
organization, video quality, learning evaluation, learning analysis and social interaction are design quality of MOOCs is incorporated into the model.

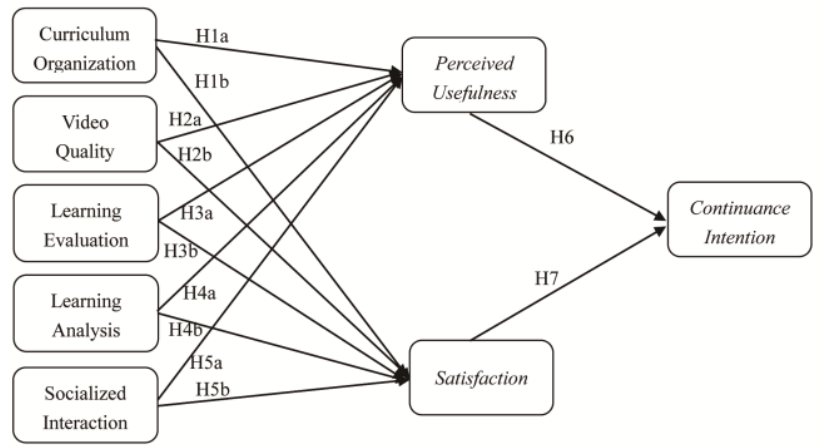

Fig. 1. Research model.

\section{A. Curriculum Organization and Video Quality}

Curriculum organization can be defined as the detailed level of the courses' teaching plan, the clarity of learning objectives. Video quality refers to the quality of video of MOOCs content, including the teacher's teaching clarity, the speed of teacher's lecture, the resolution of video. Previous studies showed that curriculum organization and video quality has positive effect on perceived usefulness and satisfaction (Cheng et al., 2014). Thus, we propose the following rese arch hypotheses:

H1a: Curriculum organization has a positive effect on the perceived usefulness of MOOCs.

H1b: Curriculum organization has a positive effect on the satisfaction of MOOCs.

$\mathrm{H} 2 \mathrm{a}$ : Video quality has a positive effect on the perceived usefulness of MOOCs.

$\mathrm{H} 2 \mathrm{~b}$ : Video quality has a positive effect on satisfaction of MOOCs.

\section{B. Learning Evaluation,Learning Analysis and Socialized Interaction}

Learning evaluation is closely related to learning objectives and course content, including two dimensions says electronic evaluation (or machine judgment) and peer evaluation. Learning analysis can be defined as a teaching tool that can monitor learning process, identify difficulties, find learning patterns, provide learning feedback, and support learners' selfreflection. Socialized interaction refers to the interaction between MOOCs learners and teachers or peers. Thus, we propose the following research hypotheses:

H3a: Learning evaluation has a positive effect on the perceived usefulness of MOOCs.

$\mathrm{H} 3 \mathrm{~b}$ : Learning evaluation has a positive effect on the satisfaction of MOOCs.

H4a: Learning analysis has a positive effect on the perceived usefulness of MOOCs.

H4b: Learning analysis has a positive influence on the satisfaction of MOOCs.
H5a: Socialized interaction has a positive effect on the perceived usefulness of MOOCs.

H5b: Socialized interaction has a positive influence on the satisfaction of MOOCs.

\section{Perceived usefulness and satisfaction}

Previous studies showed that perceived usefulness and satisfaction are key motivators on continuance intention (Bhattacherjee, 2008). Thus, we propose the following research hypotheses:

H6: Perceived usefulness has a positive effect on the continuance intention of MOOCs.

H7: Satisfaction has a positive effect on the continuance intention of MOOCs.

\section{RESEARCH METHOD}

In this study, a survey is employed to test the hypotheses formulated in the previous sections; questionnaire development and data collection are discussed in the subsequent sections.

\section{A. Questionnaire development}

We used a questionnaire survey with two sections to test our theoretical model. The first section includes demographic questions about the participants, whereas the second section features questions measuring the constructs in the research model. Considering the design quality of MOOCs, the research model consisted of eight constructs, which were measured using multiple item perceptual scales. The measurement items of curriculum organization, video quality, learning evaluation, learning analysis and socialized interaction referred to the literature of Yousef et al. (2014) and Keung (2016) .Each questionnaire item corresponding to the constructs was measured using a seven-point Likert scale, anchored on "1strongly disagree" and "7-strongly agree".

\section{B. Data collection}

The target participants of this study were those with experience with MOOCs. We sent online surveys by www.Sojump.com to those who were members of a MOOCs platform. We used the paid service of www.Sojump.com. Overall, a total of 497 MOOCs learners were invited to participate in survey, then we remove invalid samples, 271 samples were valid, effective rate was $54.5 \%$.And all the respondents were Chinese from tier cities in China. The demographics of the respondents as following.

The most commonly used MOOCs platforms are: Chinese university MOOC (55.15\%), Coursera (27.94\%), edx(15.81\%), Udacity (13.6\%), Tsinghua university online (14.34\%), and others (4\%).In terms of gender, $37.87 \%$ were male and $62.13 \%$ were female. In terms of age, the age of 18 to 23 is $26.47 \%$, $51.1 \%$ in $24-30$ years, $17.28 \%$ in $31-40$ years old and $4.79 \%$ in 40 years old. In terms of career, $55.15 \%$ respondents are enterprise staff, $17.65 \%$ are students, $24.6 \%$ are teachers, and $13.6 \%$ are government civil servants, doctors and other professionals. 


\section{DATA ANALYSIS}

In analyzing the collected data, we followed a two-step procedure (Anderson \& Gerbing, 1988). First, we examined the fitness and the construct validity of the proposed measurement model by assessing reliability, convergent validity, and discriminant validity. Then, we examined the structural model to investigate the strength and direction of the relationships among the theoretical constructs. In this study, Partial Least Squares PLS were used to analyze the reliability and validity of the model.

\section{A. Measurement model}

Reliability was assessed using Cronbach's alpha. All multiitem constructs should meet the guidelines for a Cronbach's alpha of greater than 0.70.Convergent validity was assessed based on the criterion that the indicator's estimated coefficient was significant on its posited underlying construct factor. Fornell and Larcker(1981) recommend three criteria to evaluate the convergent validity. All these three criteria are: all itemfactor loadings $(\mathrm{k})$ should be significant and exceed than 0.7; composite reliabilities (CR) for each construct should exceed 0.7; and the average variance extracted (AVE) for each construct should be greater than 0.50 . Table I demonstrates that item loading, the AVE, CR and Cronbach's alpha values for all constructs in the measurement model exceeded the recommended threshold values. In sum, the adequacy of the measurement model indicated that all items were reliable indicators of the hypothesized constructs.

TABLE I. CONSTRUCT RELIABILITY AND CONVERGENT VALIDITY

\begin{tabular}{|c|c|c|c|}
\hline \multirow{2}{*}{ Construct } & \multicolumn{3}{|c|}{ Reliability and validity } \\
\cline { 2 - 4 } & Cronbach's $\boldsymbol{\alpha}$ & $\boldsymbol{C .} \boldsymbol{R}$. & $\boldsymbol{A} \boldsymbol{V}$ \\
\hline Curriculum Organization & 0.721 & 0.827 & 0.545 \\
\hline Video Quality & 0.717 & 0.840 & 0.637 \\
\hline Learning Evaluation & 0.736 & 0.835 & 0.558 \\
\hline Learning Analysis & 0.732 & 0.832 & 0.554 \\
\hline Socialized Interaction & 0.736 & 0.834 & 0.557 \\
\hline Perceived Usefulness & 0.751 & 0.858 & 0.667 \\
\hline Satisfaction & 0.786 & 0.862 & 0.610 \\
\hline Continuance Intention & 0.749 & 0.856 & 0.665 \\
\hline
\end{tabular}

Discriminant validity was assessed based on the squared correlations between variables and their extracted respective average variance. To test the discriminant validity, the average variance shared between a construct and its measures should be greater than the variance shared by the construct and any other constructs in the model (Fornell \& Larcker, 1981).For the correlation analysis shown in Table II, the extracted average variance value for the reflective variables is consistently greater than the off-diagonal squared correlations, suggesting satisfactory discriminant validity among variables.

\section{TABLE II. INTER-CONST RUCT CORRELATIONS AND DISCRIMINANT}

\begin{tabular}{|c|c|c|c|c|c|c|c|c|}
\hline \multirow{2}{*}{ Construct } & \multicolumn{7}{|c|}{ Discriminant Validity } \\
\cline { 2 - 9 } & LE & LA & CI & PU & SA & SI & CO & VQ \\
\hline LE & .747 & & & & & & & \\
\hline LA & .585 & .745 & & & & & & \\
\hline CI & .477 & .557 & .815 & & & & & \\
\hline PU & .501 & .608 & .675 & .817 & & & & \\
\hline SA & .566 & .664 & .737 & .747 & .781 & & & \\
\hline SI & .584 & .645 & .426 & .527 & .544 & .746 & & \\
\hline CO & .639 & .675 & .607 & .605 & .664 & .517 & .738 & \\
\hline VQ & .54 & .641 & .526 & .539 & .597 & .505 & .617 & .798 \\
\hline
\end{tabular}

\section{B. Structural Equation Model}

The 12 hypotheses presented above were tested collectively using structural equation modeling (SEM) implemented via partial least squares (PLS).Figure 2 illustrates the $\mathrm{R}^{2}$ and the resulting path coefficients of the proposed research model. Table III described the results obtained from the PLS analysis. The 8 hypotheses were supported, and 4 hypotheses had not reached significant levels. In terms of the variance of the interpretation, the study model explained the variance of the persistent use of MOOCs with $57.8 \%, 46.9 \%$ perceived usefulness, and $55.8 \%$ satisfaction.

TABLE III. MODEL PATH ANALYSIS

\begin{tabular}{|c|c|c|c|}
\hline \multirow{2}{*}{ The hypothesis } & \multicolumn{3}{|c|}{ Path Coefficient and significant } \\
\cline { 2 - 4 } & Path Coefficient & P-value & Support \\
\hline H1a & 0.272 & 0.001 & Yes \\
\hline H1b & 0.286 & 0.000 & Yes \\
\hline H2a & 0.133 & 0.099 & No \\
\hline H2b & 0.160 & 0.017 & Yes \\
\hline H3a & 0.037 & 0.613 & No \\
\hline H3b & 0.093 & 0.145 & No \\
\hline H4a & 0.215 & 0.018 & Yes \\
\hline H4b & 0.250 & 0.003 & Yes \\
\hline H5a & 0.158 & 0.047 & Yes \\
\hline H5b & 0.100 & 0.117 & No \\
\hline H6 & 0.280 & 0.001 & Yes \\
\hline H7 & 0.528 & 0.000 & Yes \\
\hline
\end{tabular}

\section{DISCUSSION}

This study primary discussed the influence of perceived usefulness, satisfaction and MOOCs design quality factors in the ECM-IT model on the continuous use intention of MOOCs. Overall, 8 out of 12 hypotheses are supported by the data. 


\section{A. The impact of curriculum organization and video quality}

Research showed that curriculum organization on perceived usefulness $(p=0.272, p=0.001)$ and satisfaction $(p=0.286, p$ $=0.000)$ has a direct impact, and through them indirectly influence on continuance intention. Which requires the MOOCs teachers and administrators should try best to improve the quality of MOOCs course, in order to attract and keep learners. In addition, the research showed that video quality had not a significant positive effect on perceived usefulness ( $\mathrm{p}$ $=0.133, \mathrm{p}=0.099)$, but had not a significant positive effect on satisfaction $(\mathrm{p}=0.160, \mathrm{p}=0.017)$, and indirect effect on continuance intention. Thus, we suggest that administrators should to improve video quality and to keep a certain help for learners of MOOCs.

\section{B. The impact of learning analysis and learning evaluation}

Research shows that learning analysis on perceived usefulness $(\mathrm{p}=0.215, \mathrm{p}=0.018)$ and satisfaction $(\mathrm{p}=0.250, \mathrm{p}$ $=0.003$ ) has a direct impact, and indirectly influence on continuance intention. We suggest that the c administrators should to improve the learning analysis functions on MOOCs platform. In addition, learning evaluation was not significant in the perceived usefulness $(\mathrm{p}=0.037, \mathrm{p}=0.613)$ and satisfaction $(\mathrm{p}=0.093, \mathrm{p}<0.145)$.It is possible that the learning evaluation service in MOOCs platform is still not perfect, which can not provide a good experience for users.

\section{The impact of socialized interaction}

Structural model verification showed that the social interaction of MOOCs had a significant impact on perceived usefulness $(p=0.158, p=0.047)$, but not significant for satisfaction ( $\mathrm{p}=0.100, \mathrm{p}=0.117)$.In other words, users feel that it is helpful for teachers or students to interact with them when they study in MOOCs, but they are not satisfied with the current social interaction services. In this regard, we think it is possible that the decline in service quality caused by the explosion of the registration number of MOOCs platform makes the interaction between teachers and users of MOOCs an obstacle. Therefore, how to improve the quality of social interaction service is an important issue in MOOCs development.

\section{CONCLUSION}

Based on the ECM-IT model, the research model was constructed by introduced MOOCs design quality factors and the following conclusions were obtained through empirical analysis. First, the perceived usefulness and satisfaction in the classical ECM-IT model are still the core factors that influence on the intention of continuous using. Secondly, from the design quality of MOOCs, the course organization, learning analysis and socialized interaction have significant influence on learners' continuance intention. Third, the impact of learning evaluation on the continuous use of intention has not been verified in this study, but it does not mean that it is not important. It may be that the service has not met the expectation of learners at present. Further research is expected to help generalize our findings and future discussions the influence of learning evaluation on MOOCs using.

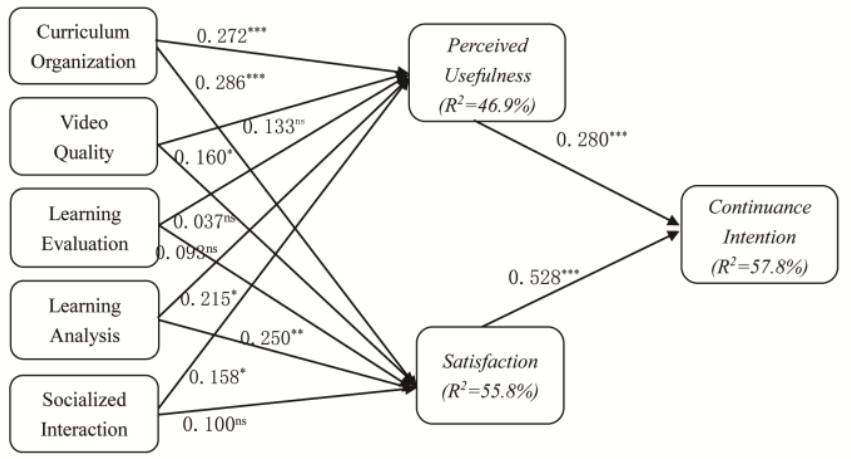

Fig. 2. Structural Equation Model PLS Result

\section{ACKNOWLEDGMENT}

This work was supported in part by grants from HangZhou Dianzi University Humanities and Social Science Fund(NO.2017B08) and Zhejiang Information and Economic and Social Development Research Center(NO.16XXHJD08).

\section{REFERENCES}

[1] T. Liyanagunawardena, A. Adams, and S. Williams, "MOOCs: A systematic study of the published literature 2008-2012," International Review of Research in Open and Distance Learning, vol. 14, no. 3, pp. 202-227, 2013.

[2] Jia Jieyou,Miu Jingming ,Wang Qiong. Big data analysis of MOOC learning behavior and effect-taking 6 MOOCs of Peking University as an example [J]. Industry and Information Technology Education,09:2329, 2014.(In Chinese)

[3] Breslow, L., Pritchard, D. E., DeBoer, J., Stump, G. S., Ho, A. D., \& Seaton, D. T.Studying learning in the worldwide classroom: Research into edX's first MOOC. Research \& Practice in Assessment, Vol. 8, no. 1, pp. 13-25, 2013.

[4] K. Alraimi, H. Zo, and A. Ciganek, "Understanding the MOOCs continuance: The role of openness and reputation," Computers \& Education, vol. 80, pp. 28-38, JAN 2015.

[5] Y.Genfu. Study on the influencing factors of MOOC users' continuous use behavior [J]. Open Education Research, 2016, 22(01):100-111. (In Chinese)

[6] L. Huang, J. Zhang, and Y. Liu, “Antecedents of student MOOC rev is it intention: Moderation effect of course difficulty," International Journal of Information Management, vol. 37, no. 2, pp. 84-91, APR,2017.

[7] Bhattacherjee, A., J. Perols and C. Sanford, Information technology continuance: a theoretic extension and empirical test. Journal of Computer Information Systems, 2008. 49(1): p. 17-26.

[8] J. Qiang, Z. Wei, L.Song, Z. Yan. Empirical research on the specification of design quality in the context of low completion rate of MOOCs [J]. EEducation Research, 2016, 37(01): 51-58. (In Chinese)

[9] T. Huanghuang, C.Yafang, X.Xiaoxiong, H. Chenglong, Z. Xicheng. Research on the quality of instructional design of Massive Online Courses [J]. The Chinese Journal of ICT in Education, 2017, (06):1-7. (In Chinese) 